\title{
Gender, Entrepreneurial Self-Efficacy, And Entrepreneurial Attitude Orientations: The Case Of The Caribbean
}

Talia Esnard-Flavius, University of Trinidad and Tobago, Trinidad

\begin{abstract}
Women owned business is increasingly becoming an important part of the entrepreneurial process. As such, there is an ongoing effort in the entrepreneurial field to understand the factors that shape their entrepreneurial attitude orientations (EAOs) and by extension, their entrepreneurial behavior. Given such importance, this paper advances local research in this field through the application of the integrated social cognitive theory to the understanding of the interplay between gender, entrepreneurial self-efficacy (ESE), and students' EAOs. Using a survey of 539 Caribbean students from higher education institutions in Trinidad, the study found that while gender acts as a weak determinant of students $\operatorname{ESE}(r=0.115, p=0.08)$, it has insignificant associations with EAOs ( $r=0.45, p=.305)$. Furthermore, the study did not find any support for expected variations in students' perception of their ESE and EAOs based on gender. On the other hand, ESE as a personal and social construct proved to have both indirect and indirect effects on students' perceptions of the EAOs. In that regard, it produced a Pearsons $r$ of $(.0464, p=0.01)$ and showed mediating and inverse effect on the relationship between gender and EAOs. Implications of these findings for researchers and policy makers are discussed and areas for further research are outlined.
\end{abstract}

Keywords: gender; entrepreneurial self-efficacy; entrepreneurial attitude orientations; social cognitive theory; Caribbean

\section{INTRODUCTION}

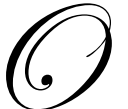

ver the last decade, there has been a noted increase in the participation of women in the entrepreneurial activities around the world (Minitti, Arenius, \& Langowitz, 2005). As such, women play a substantial role in entrepreneurship throughout the world (Wilson, Kickul and Marlino, 2007; Mueller and DatoOn, 2008). In that respect, 'women represent more than one third of all persons involved in entrepreneurial activity and are likely to play an even greater role when informal sectors are considered'(Minitti, Arenius, \& Langowitz, 2005, 8). However, despite their significant contribution, gender assessments across the world signal the crippling recognition that men are more likely to be involved in entrepreneurial activity than their female counterparts (Delmar and Davidsson, 2000; Reynold, Bygrave and Autio, 2004; Minitti, Arenius, \& Langowitz, 2005; Bosma and Levie, 2009). More specifically, the 2005 Global Entrepreneurship Monitor (GEM) report revealed that in both high-income ${ }^{1}$ and middle-income ${ }^{2}$ country clusters, a significant gender gap exists between male versus female entrepreneurial activity and business ownership. In the case of high-income countries, men are twice more likely to be early or established business owners than women. In middle-income countries, the gender gap is narrower particularly at the early stage but widens at the more established business level. In the case of Jamaica (as the only Caribbean island on which data is available in the 2005 GEM report), $21.65 \%$ of men are involved in early stage

\footnotetext{
${ }^{1}$ Including Australia, Belgium, Canada, Denmark, Finland, France, Germany, Singapore, United Kingdom and United States with per capita (PPP) GDP higher than USD \$20, 000.

${ }^{2}$ Including Argentina, Brazil, Chile, China, Czech Republic, Indonesia, Jamaica, Mexico, Peru, Thailand, Russia, South Africa and Uruguay with per capita (PPP) GDP lower than USD \$20,000.
} 
(nascent and new) entrepreneurial activity in comparison to $15.69 \%$ of women. In the case of established business owners, the gender differences are somewhat marginal with $9.57 \%$ of men compared to $9.49 \%$ of women. An overall examination of business owners revealed a larger gap with $31.22 \%$ men compared to $25.18 \%$ women.

Given the importance of entrepreneurship as a source of employment for women throughout the world and for economic development specifically in developing countries (Reynold, Bygrave and Autio, 2004; Acs and Storey, 2004; Acs and Audretsch, 2005), where women represents vulnerable groups, deliberate efforts at engendering the entrepreneurial spirit among women remains critical. This development agenda however requires the identification and cultivation of entrepreneurial attitudes (ACOA, 1996; European Commission, 2004), a supply process, which remains relatively unexplored in entrepreneurial research. More importantly, if women are to play an even greater, more pronounced role in entrepreneurially driven economic development, it is particularly important that we understand what factors motivate or affect their entrepreneurial attitude orientation (a predisposition to response favorably or unfavorably to entrepreneurial activities), as a relative indicator of their entrepreneurial behavior (Robinson et al., 1991; Krueger, 2005). However, despite this urgency and corresponding acknowledgement that women are one of the rising populations of entrepreneurs and that they make a significant contribution to innovation, job, and wealth creation in economies across the globe, they continue to be vastly understudied. Thus, empirical research that focuses on women, the experiences and challenges that they confront, remains wanting (Low, 2001). As such, two provocative questions that continue to face entrepreneurial research field are what factors influence entrepreneurial attitude orientations and are those factors associated with observed gender differences?

Despite the scarcity of research on EAOs continue to plague the entrepreneurial field; there is an extant body of entrepreneurial literature that seeks to understand entrepreneurial behavior and entrepreneurial activity (Brush et al., 2006). As such, many related and valuable studies have identified a variety of factors that affect entrepreneurial behavior, that is, one's propensity to establish new ventures or enhance existing ones. In the area of demographic studies, there is a growing consensus in the literature that gender, age, ethnicity, and family background are critical aspects of the entrepreneurial experience (Bird, 1993; USSBA, 1997; Anna, Chandler and Bosma and Levie, 2009). Additionally, other researchers have highlighted the relative significance of psychological aspects that pertain to personality traits or attributes including risk-taking propensity (Brockhaus, 1993) locus of control (Mueller \& Thomas, 2001), and have inculcated these measures into the ESE construct (Chen, Greene and Crick, 1998; De Noble, Jung and Ehrlich, 1999; Krueger, 2005). Equally important, is the dearth of sociological and educational research that posits that entrepreneurial education is a decisive factor in entrepreneurial attitudes and behavior (Ronstadt, 1990; Rushing, 1990).

However, despite these advances in entrepreneurial research, there are equally critical areas that remain relatively untested (Gartner, 1985; Krueger and Brazeal, 1994). As such, while several streams continue to underscore the differences between men and women in entrepreneurial activity, most empirical studies tend to study women in post-venture creation (Krueger and Brazeal, 1994; Mueller, 2004). In addressing the limitations of existing entrepreneurial research, Gartner $(1985,696)$ noted that much of the research in entrepreneurship has been one-dimensional, that is, 'focusing on one aspect of new venture creation, namely, to distinguish entrepreneurs from non-entrepreneurs or entrepreneurial firms from non-entrepreneurial firms.' The general aim of much of these studies has been to establish the characteristics of the 'entrepreneur' as well as the factors associated with his or her success. Equally important is the fact that despite the recognition by researchers that entrepreneurial education, cultural values, and personality traits influence entrepreneurial behavior, the bulk of such research fails to address the relative importance of gender, and ESE, if any, on students' EAOs, as nascent or potential source of entrepreneurs (Krueger and Brazeal, 1994; Delmar and Davidsson, 2000). This attitudinal approach for recent entrepreneurial researchers represents a crucial yet novel approach for encouraging entrepreneurial behavior (Robinson et al., 1991; Krueger, 2005). Equally important is the fact that the paucity of entrepreneurial research has been conducted primarily in more advanced and/or transitory societies like the United States, parts of Eastern Europe and Central Asia respectively, with less emphasis on developing societies like the Caribbean. This research gap (that is, the focus on the factors that shape students' EAOs in developing contexts like the Caribbean, possible gender variations, and the use of integrated theoretical frameworks in its understanding) is therefore at the core of this study. 
Given this empirical and contextual abyss, the potential contribution of this paper is therefore twofold. First, the study presents a research response to the sluggish yet progressive paradigm shift related to entrepreneurially driven economic development approaches and examines the challenge and implications of this shift for encouraging EAOs in the context of developing societies like the Caribbean. An important aspect of this paradigm shift involves a growing focus on small-scale entrepreneurs, owners of microenterprises (specifically female-owned enterprises) and the need for new research agenda that captures the processes that govern them (Ferdinand, 2001). Second, the research also acts in response to the cries of development scholars and examines gendered perceptions and formation as a way of exploring whether males are more likely than females to become entrepreneurs in developing societies. As such, the original contribution of the paper is the advancement of the theoretical and empirical basis of integrative aspects of social cognitive theory through the examination of the socio-psychological aspects (gender and entrepreneurial self-efficacy-ESE) that affect public tertiary students' EAOs in the Caribbean. Essentially, by so doing, it is hoped that such an examination can provide meaningful contributions to ongoing discussions on the processes by which we foster EAOs, particularly among women, as a vital aspect of the entrepreneurial development process in the Caribbean. The following research questions therefore guide the present study:

(i) What is the relationship between gender and students' perception of their EAOs?

(ii) Do students' perceptions of their EAOs vary by gender?

(iii) What is the relationship between gender and students' perception of their entrepreneurial self-efficacyESE?

(iv) Do students' perceptions of their ESE vary by gender?

(v) Does students' perception of their ESE mediate the relationship between gender and their EAOs?

(vi) How do students perceive gender roles as it relates to entrepreneurial activity?

(vii) How does social cognitive theory help us to understand the interplay between gender, students' perception of their ESE, and their EAOs?

\section{REVIEW OF RELATED LITERATURE}

The past sixty years can be marked by the increasing attention given to the multi-faceted nature of entrepreneurial behavior and activity. The volume of this entrepreneurial literature proposes that psychological (personality/traits), demographic (gender, age, ethnicity) and socio-cultural factors (culture and education) may provide valuable insights into entrepreneurial behavior. For the purpose of this study, related literature on gender, ESE, and entrepreneurial behavior provide valuable insights on the study.

\section{Gender and entrepreneurship}

Research on women's entrepreneurship is well-documented (Brush, 1992; Gatewood, Carter, Brush, Greene, \& Hart, 2003) and there is a consensus on the importance of gender to entrepreneurial behavior (Bird, 1993; Krueger, 2005). Generally, these studies contended that gender, as a neglected variable in entrepreneurial research, is critical to theoretical advancements in the field. More specifically, Katz, Brockhaus, and Hills (1993, 198), argued that such a demographic variable 'holds the key to improving the representativeness of entrepreneurial research.' However, despite this accord on its importance, the ambiguous findings of such studies remain a major source of contention (Muller, 2004). In that regard, one stream of research holds that that women are just as likely to display certain competencies necessary for entrepreneurial activities as men are, and as such, the entrepreneurial experiences remain comparable. In that regard, Bird (1993) cited strong similarities between men and women in their desire for autonomy, control, and achievement.

On the other hand, another stream of researchers contends that such findings are misleading as they continue to provide mixed results (Bird, 1993; Hofestede, 2001) and continue to challenge this standpoint. The major position of this second stream is that fewer women compared to men become involved in entrepreneurial careers (Bird, 1993; Minniti, Allen and Langowitz, 2005; Bosma and Levie, 2009). In particular, Bird (1993) cited many studies that reported an involvement percentage for women of less than 20, in the US, Ireland, Africa, Asia and Latin America. In addition to the above, Bosma and Harding $(2007,22)$ further specified that 'in high and middle-income countries 'the gender gap is greater among established owners than among early-stage entrepreneurs.' Looking specifically at the case of corporate employment versus entrepreneurship, Brodsky (1993) 
also noted that female managers were more comfortable in their positions within corporate organizations as opposed to women entrepreneurs who found this situation confining, suggesting an indirect link to their differences in their risk-taking propensities. Additionally, Ferdinand (2001) reported that women tended to be more cautious while men tended to be more imprudent driving them to be profit-oriented, a dichotomy that provides an empirical psychological explanation for observed differences in their participation in their entrepreneurial field. Taking a socio-cultural slant, Hofstede (2001) noted that in countries with high domineering masculinity values (as cultural manifestations of gender identity), values for men and women in the same jobs differed more than in countries with low masculinity values. Such cross-country comparisons provide empirical support for the argument that (i) the nature and extent of traditional masculine societies vary, and that, (ii) such a gendered socio-cultural framework continues to shape the entrepreneurial field. Such findings therefore illuminate the need for further research that addresses the bases and dynamics of social values that shape gender roles and/or stereotypes, and its impact on the participation of women in entrepreneurial activity.

\section{Gender roles, stereotypes, and entrepreneurship}

Women and men have historically assumed somewhat different roles in society (Muller and Dato-On, 2008). In the specific case of the labor market, evidence suggests that certain employment prospects have traditionally been considered more appropriate for men and others more appropriate for women (Williams and Best, 1982). In assessing these trends, some studies have attempted to provide causal explanations of the link between gender and labor market participation in developing societies (Ferdinand, 2001; Lisowska, 2002; Ruminska-Zimmy, 2002). Looking specifically at transition economies like Czech Republic and Poland, Ruminska-Zimmy (2002) flagged the negative effect of policies that encourage women to leave the labor market early. Ruminska-Zimmy (2002) postulated that the policies of many transition countries of the 1990s run against worldwide trends that increasingly acknowledge the role of women in the entrepreneurial process. Additionally, the author elucidated that these experiences are met with negative social responses based on the low prestige and value given to women who work outside of the home (ibid). With respect to the Caribbean, Ferdinand (2001) highlighted the triple role of the woman (caretaker, wife, child bearer) as a causal factor deterring women from engaging in entrepreneurial activities. In that regard, Ferdinand (2001) attributed the concentration of women in the informal sector to the skills acquired from household duties, the compatibility of the informal sector economic activity with their reproductive roles and the discouraging displays of social responses that follow. In African societies, Lisowska (2002) argued that various religious, social, and historical stereotypical beliefs about the typical occupational paths for men versus women and practices engrained in traditional socialization processes hinder women entrepreneurs. In particular, she suggested that some of these beliefs included the superstitious notion that the land will not produce yields if cultivated by women and the traditional identification of certain clusters of competencies for women different to that of men. In the case of cluster of competencies, women were generally perceived to be expressive, emotional, and hesitative while men were perceived to be more assertive, objective, and reckless. Lisowska (2002) linked this theoretically to the low levels of self-efficacy that these women hold and the absence of institutional and cultural processes that engendered them. Given the above, Lisowska (2002, 36) contended that there 'is an overall lack of social acceptance for women in private economic activity'. Collectively, these studies put forward the case that traditional social expectations, as it pertains to gender disparities in labor market participation and/or aspirations, explain gendered entrepreneurial patterns. These studies therefore suggest that internalized notions of appropriate labor market engagement and the low levels of entrepreneurial efficacy on the part of women warrant further investigation.

\section{Risk taking propensity, gender, and entrepreneurship}

Entrepreneurial activities occur within high-risk economic environments (Drucker, 1985; Bygrave, 1994; Bridge, O'Neil and Cromie, 2003). Flowing from this consensus is a noticeable conceptual effort at relating such risk environments to personality attributes. In this regard, the literature is pregnant with studies that suggest that entrepreneurs take calculated risks (Schumpeter, 1934; Casson, 1982; Kirzner, 1997). This argument points to taken for granted understandings of people's willingness and ability to access and assess unpredictable situations, thereby enabling a calculated process of decision-making (Langlois, 2001). Early applied studies confirm that enterprising people are moderate risk-takers (Shapero and Sokol, 1982; Brockhaus, 1987). Others researchers however call for a more cautious interpretation of such results based on empirical evidence of imperfect market functioning, the tautological weakness of the risk-taking construct, and the failure of such studies to disaggregate those findings 
based on demographic characteristics like gender (Langlois, 2001). In the case of the latter, applied studies, produce inconsistent findings. As such, more recent studies fill in that research void and claim that women are less inclined to take risks, while other studies hold that female entrepreneurs have the same risk taking propensity as men (Muller and Dato-On, 2008).

Other researchers have also explored the importance of locus of control to risk taking propensity and entrepreneurial behavior (Rotter, 1966; Ward, 1993; Muller and Thomas, 2001). Some researchers argued that internal locus of control produces greater control of external risks and/or what happens in their lives, based on evidence of some correlation between internal locus of control and individual autonomy (Bandura, 1986). Empirical studies have linked internal locus of control to entrepreneurial success (Ward, 1993). In particular, Ward (1993) found that persons with internal locus of control tend to be proactive in dealing with associated entrepreneurial risks by estimating the probability of business failure and adjust the activities of their business accordingly. To date, although some consensus is evident, there is no clear-cut difference between the two and as such, analyses draw attention away from causal explanations of these attributes. More specifically, one of the major limitations of locus of control as a construct is its focus on individuals' belief in the power of their own actions and the subsequent neglect of social processes that shape them. As such, some researchers advocate the need for conceptualizations based draw on the significance of cognitive process, in particular, individuals' perception of their ability as it pertains to individual tasks (Boyd and Vozikis, 1994).

\section{Cognition, entrepreneurial self-efficacy, and entrepreneurship}

Increasingly, there is some consensus that cognitive processes play a critical role in social behavior and thought (Bandura, 2001; Krueger, 2005). As such in relating such theoretical approaches to entrepreneurial studies, Krueger $(2005,105)$ contended that 'understanding entrepreneurial cognition is imperative to understanding the essence of entrepreneurship, how it emerges and evolves'. Drawing on the importance of cognition, some researchers have emphasized the role of perceived self-efficacy to human behavior and attitudes (Bandura 1986, 1991; Chen, Greene and Crick, 1998; De Noble, Jung and Ehrlich 1999). As a pioneer in the psychological field, Bandura (1986, 391) defined perceived self-efficacy as 'people's judgments of their capabilities to organize and execute courses of action required to attain designated types of performances.' Inherent in this definition is the notion that self-efficacy as a social cognitive process mediates the relationship between knowledge and human action. Early research links entrepreneurial self-efficacy to entrepreneurial intentions (Bird, 1988; Boyd and Vozikis, 1994). As such, Boyd and Vozikis (1994) suggested that the presence of high entrepreneurial self-efficacy and entrepreneurial intentions in early career development would produce strong probabilities of entrepreneurial activity later in life. Other more recent studies have documented the theoretical significance of ESE and have convincingly showed that individuals with higher ESE have higher entrepreneurial intentions (Krueger, 2000; Mau, 2003; Baum and Locke, 2004). More importantly, empirical incorporations of ESE into entrepreneurial behavior or intentions models have provided increased explanatory and predictive value (Krueger, Reilly, and Casrud, 2000). In the area of gender and entrepreneurship, research suggests that women have lower ESEs than men do (Chen et al. 1998; Bandura, 2001). More specifically, Bandura (2001) found significantly lower levels of self-efficacy among women in careers historically seen as non-traditional for women. Given this finding, other studies claim that women are more likely to limit their career aspirations than that of men (Bosma and Levie (2009). Stemming from the above, other researchers in the entrepreneurial field call and provide support for continuous conceptual refinement of self-efficacy, which incorporates more tasks that are specific based indicators related to the entrepreneurial domain (Chen, Greene and Crick, 1998; De Noble et. al. 1999; McGee et al. 2009).

\section{THEORETICAL FOUNDATION}

\section{Social Cognitive theory}

The multidisciplinary nature of the social cognitive theory presents a dynamic approach that engages in a scientific study of 'how people's thoughts, feelings, and behaviors are influenced by the actual, imagined, and implied presence of others' (Allport 1985, 3). The hallmark of such an approach therefore is its claim that social interaction informs cognitive processes via a triadic reciprocal process in which behavior, personal factors and environmental events all operate as interacting determinant of each other. Bandura $(1997,9)$ clarifies, 'it is largely 
through their actions that people produce environmental conditions that affect their behavior in a reciprocal fashion. The experiences generated by behavior also partly determine what a person becomes and can do which in turn, affects subsequent behavior'. By extension, when one alters their evaluation or approach to the environment, these experiences will also be different based on personal characteristics of age, ethnicity, and gender.

On the premise of reciprocal determinism, these environmental factors interact with unique personal factors. In this regard, Bandura (1989) introduced five basic and unique human capabilities (symbolizing, forethought, observational learning, self-efficacy and self-reflection) that provide them with the cognitive and evaluative means of mitigating the above process. Symbolizing, as a theoretical construct operates through the identification and illumination of the importance of symbols as the mechanism for engaging in cognitive thought processes based on observations (as attitudinal or behavioral guides) for future courses of action about the environment. Forethought speaks of the 'person's capacity to motivate him/her and guide his/her actions anticipatorily' (Bandura, 1989). The theory postulates that these self-regulatory mechanisms mediate external influences and becomes the theoretical basis for self-efficacy (one's belief in his/her ability to reproduce behavior or attitude) thereby allowing individuals to have some extent of personal control over their thoughts and actions, motivations and feelings (Bandura, 1989). Self-efficacy as a personal and social construct remains one of the core concepts of social cognitive theory (Bandura, 2001; Luthans and Ibrayeva, 2006). This for Bandura $(1986,391)$ is 'people's judgment of their capabilities to organize and execute courses of action required to attain designated types of performances'. Thus, embedded in the social cognitive theory are the related constructs of self-regulation and self-reflection. With reference to the former, it reflects an overriding general principle that places greater emphasis on the ways in which personal factors mediate the relationship of the environment to adopted behavior or attitudes. Self-reflection, more specifically, points to people's capacity to reflect upon and internalize their own successes or failures. One achieves the latter when he or she identifies that ability to perform. These personal cognitive processes however are not devoid of social influences, in which for Bandura $(1986,19)$ 'virtually all learning phenomena, resulting from direct experience, can occur vicariously by observing other people's behavior and its consequences for them' This capacity to learn by observation also becomes the basis upon which individuals generate and regulate their own attitudes and behaviors.

Given these possibilities, the growing applicability of this social cognitive theoretical framework in entrepreneurial studies continues. The applied value of the social cognitive theory is well documented in evidencebased research (Casrud and Johnson, 1989; Robinson et al., 1991; Luthans, Stajkovic, and Ibrayeva, 2000). Within recent times, Luthans and Ibrayeva (2006), using the social cognitive framework, explored the nature of entrepreneurs personal characteristics, environment and ESE in Central Asian transition economies. Their examination revealed that ESE had direct and mediating effects on performance. Other entrepreneurial research findings also provide sources of support (Boyd and Vozikis, 1994; Krueger and Brazeal, 1994).

Factoring all of these theoretical and empirical insights into consideration, the line of reasoning for this study therefore is that the use of social cognitive theory can potentially offer some significant insight into the dynamic process in which gender, ESE, affect their EAOs of tertiary students' in the Caribbean. EAOs in this case, embraces and adopts the tested and proven allportian measure of entrepreneurial attitude as developed by Robinson et al. 1991, in which questions of the critical troika of affective, cognitive, and behavioral aspects of entrepreneurial attitudes were measured. Given the theoretical concepts and the relationship between them, the research proposes the following:

$\mathbf{P}_{1}$ : There is positive relationship between gender and EAOs.

$\mathbf{P}_{2}$ : $\quad$ Students' perception of their EAOS varies by gender.

$\mathbf{P}_{3}$ : There is a positive relationship between gender and ESE

$\mathbf{P}_{4}$ : Students' perception of their ESEs positively correlates with their EAOs.

$\mathbf{P}_{5}$ : Students' perception of their ESE varies by gender.

$\mathbf{P}_{6}$ : Students' perception of their ESE will mediate the relationship between gender and their EAOs. 


\section{METHOD}

The purpose of the study is both to advance theoretical premises of social cognitive theoretical framework and to extend its application to study of EAOs in the Caribbean. Given the above and the limited accessibility to educational institutions, this study capitalized on the use of a cross-sectional survey research design.

\section{Sample frame and sample}

The sample frame consisted of 4, 555 Caribbean students enrolled in social science degree programs within public and semi-public tertiary institutions in Trinidad. These institutions included the University of the West Indies (44.5\%), the Trinidad and Tobago Hospitality Institute (7.4\%), the Cipriani College of Labor and Cooperate Studies (36.7\%) and the Arthur Lok Jack Graduate School of Business (11.4\%). Using systematic random sampling, 539 students completed a self-administered questionnaire. The sample consisted of 303 females or $56.22 \%$ of the sample and 226 males or $41.93 \%$ of the sample. With respect to age, there were 255 students (or $47.3 \%$ of the sample) in the 20-29 cohort, 108 (or 20\% of the sample) in the 30-39 cohort, and 89 (or 16.5\% of the sample) in the 40-49 cohorts. Additionally, 44 students (or $8.2 \%$ of the sample) and 22 students (or $4.1 \%$ of the sample) were in the below 20 and over 50 years category respectively.

\section{MEASURES}

\section{Entrepreneurial self-efficacy (ESE)}

EESE as a theoretical and empirical construct (Luthans and Ibrayeva, 2006) covers multi-dimensional aspects of new venture creation (Chen et al. 1998). Given the above, the study measured students' perceived ESE using the instrument developed by De Noble, Jung, and Ehrlich (1999), which consists of a set of items that asks the respondent to self-assess his or her ability to perform certain entrepreneurial tasks. These entrepreneurial tasks included developing new products and market opportunities, building an innovative environment, initiating investor relationships, defining core purpose, coping with risks, and developing human resources. The study subjected all responses to a 5-point likert scale where 1 represents strongly disagree and 5 strongly agree. The composite Cronbach alpha score was 0.7545 .

\section{Entrepreneurial Attitude Orientations (EAOs)}

Robsinon et al. (1991) work provides the study with valuable four-dimensional measures of achievement, innovation, perception of personal control and perceived self-esteem for EAOs. While utilizing the core dimensions of the scale, the final EAO measure omitted the self-esteem component of the original scale as this was captured in the ESE scale treated as an independent predictor. It was replaced with cognitive questions on feasibility and desirability of entrepreneurship. The revised scale consisted four main sub-scales: (i) entrepreneurial achievement attitude (affective), (ii) perceptions of entrepreneurship based on feasibility, desirability, respectability, and viability (cognition), (iii) personal control over failure, goals, dreams and their future (conation), and (iv) judgment or consideration of entrepreneurial tasks (innovation). Together, the scale forms an EAO index with scores ranging from 16-80 using the likert scale ranging from 1-strongly disagrees to 5-strongly agree. The Cronbach alpha composite score for this EAO scale was 0.7960 .

\section{RESULTS}

\section{Gender and EAOs}

$\mathbf{P}_{1}$ : There is positive relationship between gender and EAOs

In order to test the first proposition, the researcher performed quantitative and qualitative assessments. In the case of first instance, the researcher correlated gender with students' perception of their EAOs using the Pearson's $R$ statistic. Results revealed insignificant correlations between gender and students' perception of their EAOs, with Pearson's $R$ of $(.045, \mathrm{p}>.305)$. This statistic implies that observed differences in students' EAOs is 
marginal. Relatedly, the Adjusted $\mathrm{R}^{2}$ between gender and EAOs was $(0.000, \mathrm{p}>.305)$, suggesting that gender does not hold predictive value for understanding students' EAOs.

In the case of qualitative assessments, thematic analyses of responses showed no signs of sharp differences in ideas of gender roles and that both male and female students thought that there was a lot to be done to improve the EAOs across the board. In some cases, male students reported that they possessed what has been identified as typical feminine qualities including the need for secured, stable, and risk free environments. In terms of female students, although some continued to identify with historical roles of a woman, others questioned the credibility of such notions based on the increasingly changing roles of the women in the workforce. The following statements reflect some of these ideas.

42-year-old Male: "I prefer a secured, comfortable lifestyle where there is little risk towards my financial security and peace of mind". [Uncertainty avoidance]

42-year-old Female: "Things at present are changing and where it was a man's world, women are now making waves". [Gender]

$\mathbf{P}_{2}$ : $\quad$ Students' perception of their EAOs varies by gender.

An initial comparison of the gendered mean scores for students' EAOs showed relatively close means with 64.7426 and 65.3318 for females and males respectively with a corresponding standard deviation of 6.29357 and 6.78414. In the case of the latter, the standard error of the mean is smaller for female students with (.36156) in comparison to male students with (.45430). This suggests that the EAO scores for females are closer around the mean average than that of male students in the sample. However, in order to provide conclusive evidence that shed light on speculation of differences, the researcher utilized the independent sample $\mathrm{t}$-test. In order to execute the $\mathrm{t}$ test, the researcher converted the categorical nature of the gender variable into an interval level of measurement using the dummy variable where zero represents female respondents and one male respondent. Using Levene's test for equality of variance, the F statistic calculated was $1.137(\mathrm{p}>0.287)$ and the t-test for equality of mean was ($1.027, \mathrm{p}>.305)$ this shows that these marginal differences remain insignificant. Given this result of the 95\% confidence in the interval of differences, the researcher assumed equal variance between gender groups. The totality of the test is shown in table 1.1 below.

Table 1.1

Gender and EAOs

\begin{tabular}{|c|c|c|c|c|c|c|c|c|c|c|}
\hline & & $\begin{array}{c}\text { Levene's } \\
\text { test for } \\
\text { equality } \\
\text { of } \\
\text { variances } \\
\text { F }\end{array}$ & Sig. & $\begin{array}{c}\text { t-test for } \\
\text { equality } \\
\text { of means } \\
t\end{array}$ & df & $\begin{array}{l}\text { Sig. (2- } \\
\text { Tailed) }\end{array}$ & $\begin{array}{l}\text { Mean } \\
\text { differ- } \\
\text { ence }\end{array}$ & $\begin{array}{c}\text { Std. } \\
\text { error } \\
\text { differ- } \\
\text { ence }\end{array}$ & $\begin{array}{c}95 \% \\
\text { Conference } \\
\text { interval of the } \\
\text { difference } \\
\text { lower }\end{array}$ & \\
\hline ENTATOR2 & $\begin{array}{l}\text { Equal } \\
\text { variances } \\
\text { assumed } \\
\text { Equal } \\
\text { variances } \\
\text { not } \\
\text { assumed }\end{array}$ & 1.137 & .287 & $\begin{array}{l}-1.027 \\
-.1015\end{array}$ & $\begin{array}{c}524 \\
457.396\end{array}$ & $\begin{array}{l}.305 \\
.311\end{array}$ & $\begin{array}{l}.5893 \\
-.5893\end{array}$ & $\begin{array}{l}.57402 \\
.58061\end{array}$ & $\begin{array}{l}-1.71693 \\
-1.73026\end{array}$ & .55173 \\
\hline
\end{tabular}

Note: ENTATOR2 is the dependent variable, that is, EAOs

$\mathbf{P}_{3}: \quad$ There is a positive correlation between gender and ESE.

Quantitative and qualitative assessments were also performed to test this proposition. In the case of first instance, the researcher correlated gender with students' perception of their ESE using the Adjusted $R^{2}$ statistic. 
Results revealed a weak positive correlation between gender and students' perception of their ESE, with Adjusted $R^{2}$ of $(.115, \mathrm{p}<.008)$. This statistic implies that observed differences in students' ESE evident but remains low. Relatedly, the Adjusted $\mathrm{R}^{2}$ for gender and EAOs was $(0.11, \mathrm{p}<0.08)$ accounting for $11 \%$ of the variance observed in their ESEs.

Qualitative analyses of ESE among students revealed comparative perceptions, albeit the presence of some distinctions. In that case, both expressed skepticism on the extent of their perceived ESE and a general need for improvement therefore on both counts. However, for a few students historical gender stereotypes continue to be internalized, thereby affecting the ESEs. The following reflects some of these observations.

42-year-old Female: "With my background and education, I still did not believe in myself, only when there was a change in my heart to know I see myself making plans and objectives for some life change". [Education and selfefficacy]

23-year-old Male: "One may have the educational skills but need the passion, drive, dedication, drive, and values to be in a business". [Self-efficacy and cultural values]

32-year-old Male: "We need to take risk and implement proper controls to execute efficiency". [Self-efficacy]

35-year-old Female: "If women are taught the value of self-efficacy and working independently of 'governments" cultures, like that of the public service, as well as recognizing that rewards come from self-reliance and goal setting that would succeed just as well". [ cultural values, entrepreneurial self-efficacy, motivation]

42-year-old Male: "Both men and women should be taught that there is no need to be vindictive and jealous but to know that earth still has wealth for everyone to enjoy. By letting each one see himself/herself as the next Bill Gates and believing it". [Self-efficacy]

29-year-old Female: "Women need to be taught how to be more innovative and assertive from an early age". [Entrepreneurial self-efficacy]

$\mathbf{P}_{4}: \quad$ Students' perception of their ESEs positively correlates with their EAOs

Theoretically, self-efficacy mediates the relationship between environmental factors and human behavior (Chen, Greene, and Crick 1998; Bandura 2001). In order to test this theoretical claim the researcher assessed the Pearson's Standardized $r$ statistic for correlations between students' perception of their ESE and their EAOs. Results revealed that a moderate to near substantial positive relationship $(.464, \mathrm{p}<0.01)$. This suggests that students' perception of their ESE can play a significant role in fostering their EAOs. In order to confirm this speculation, regression analysis as explored through examinations of standardized regression $\left(R^{2}\right)$, the corresponding beta value, and the $\mathrm{F}$ ratio were performed. Findings uncovered an adjusted $\mathrm{R}^{2}$ of .215 , which reflects a real trend in the population thereby substantiating initial speculation of its' predictive value as ESE accounts for approximately $22 \%$ of the variance in students' entrepreneurial attitude orientations. Table 1.2 captures the above.

Table 1.2a

Regression model for ESE on EAOs

\begin{tabular}{|c|c|c|c|c|}
\hline Model & R & R-Square & Adjusted R-Square & Std. Error of the Estimate \\
\hline 1 & .464 & .215 & .214 & 5.77510 \\
\hline
\end{tabular}

Note: Predictors: (Constant), ENT_SE

Of equal importance is the ANOVA test of the regression model that expands on the findings of the above. The ANOVA statistics showed that with a high $\mathrm{F}$ value of $(144.193, \mathrm{P}<0.000)$. This also provides confirmation of the explanatory and predictive value of ESE where an increase in students' perception of their ESE is expected to increase their perceptions of their EAOs. Table $1.2 \mathrm{~b}$ below provides details of the above. 
Table 1.2b

ANOVA test for regression model for ESE and EAOs

\begin{tabular}{|l|c|c|c|c|c|}
\hline \multicolumn{1}{|c|}{ Model } & $\begin{array}{c}\text { Sum of } \\
\text { Squares }\end{array}$ & Degrees of Freedom & Mean Square & F-Statistic & Sig. \\
\hline 1 Regression & 4809.085 & 1 & 4809.085 & 144.193 & .000 \\
Residual & 17509.686 & 525 & 33.352 & - & - \\
Total & 22318.770 & 526 & & - & - \\
\hline
\end{tabular}

Note: Predictors: (Constant), ENT_SE and Dependent Variable: ENTATOR2, that is, EAOs.

Equally important, table 1.2c below also showed the significance of this relationship. Significant regression co-efficients between ESE and EAOs indicated beta value (B) of .464 (a confirmation of Pearson's $R$ ) and the $\mathrm{t}$ value of (12.008, $\mathrm{p}<0.000)$. Additionally, the collinearity statistics illuminated any speculation that this variable interacts with another variable. The VIF value or variable inflation factor of one also confirms this. De Vaus $(2002,382)$ stated that 'if the VIF values are greater than 5, then multicollinearity will serve as a problem that affects the findings and its' interpretation'. The same table below showed that the VIF value in this regression model is 1.000 and thus removed the threat of multicollinearity.

Table 1.2c

Regression co-efficient for ESE and EAOs

\begin{tabular}{|c|c|c|c|c|c|c|}
\hline & \multirow{2}{*}{ UCB } & \multirow{2}{*}{ Std. Error } & \multirow{2}{*}{ SCB } & \multirow{2}{*}{ T } & \multicolumn{3}{|c|}{ Sig. Collinearity Statistics } \\
\cline { 5 - 8 } & & & \multicolumn{2}{|c|}{ Tolerance } & VIF \\
\hline ENT_SE & 42.414 & 1.896 & & 22.371 & .000 & \\
\\
\hline
\end{tabular}

Note: UCB: Unstandardized Coefficients Beta; SCB: Standardized Coefficients Beta; ENTATOR2, is the dependent variable, that is, EAOs.

$\mathbf{P}_{5}$ : $\quad$ Students' perception of their ESE varies by gender.

An initial comparison of the gendered mean scores for students' perception of their ESE showed relatively close means with 30.6295 and 31.5958 for females and males respectively with a corresponding standard deviation of 3.98316 and 4.32197. The standard error or the mean is smaller for female students with (.22808) in comparison to male students with (.28813). Similarly, as in the case of EAO scores, females are closer around the mean average than that of male students in the sample. Using the independent sample t-test, the F statistic calculated was (1.117, $\mathrm{p}$ $>0.733)$ and the t-test for equality of mean was $(-2.661, \mathrm{p}>.9660)$ clearly supporting a case of no significant differences between ESE for male and female students. Equal variance between gender groups is thus assumed. The totality of the test is shown in table 1.3 below.

Table 1.3

Gender and ESE

\begin{tabular}{|l|l|c|c|c|c|c|c|c|c|c|}
\hline \multicolumn{2}{|l|}{} & $\begin{array}{c}\text { Levene's } \\
\text { test for } \\
\text { E.0.V. }\end{array}$ & Sig. & $\begin{array}{c}\text { t-test for } \\
\text { E.0.M }\end{array}$ & Df & $\begin{array}{c}\text { Sig. (2- } \\
\text { Tailed) }\end{array}$ & $\begin{array}{l}\text { Mean } \\
\text { Diff. }\end{array}$ & $\begin{array}{c}\text { Std. } \\
\text { error } \\
\text { diff. }\end{array}$ & \multicolumn{2}{|c|}{$\begin{array}{c}\text { 95\% } \\
\text { Conference interval of the diff. } \\
\text { lower Upper }\end{array}$} \\
\hline ENTATOR2 & $\begin{array}{l}\text { Equal } \\
\text { variances } \\
\text { assumed }\end{array}$ & 1.117 & .733 & -2.661 & 528 & 0.008 & -.9660 & .36298 & -1.61910 & -.25259 \\
& $\begin{array}{l}\text { Equal } \\
\text { variances } \\
\text { not } \\
\text { assumed }\end{array}$ & & -2.629 & 459.673 & 0.009 & -.9660 & .36748 & -1.68819 & -.24391 \\
\hline
\end{tabular}

Note: ENTATOR2, is the dependent variable, that is, EAOs. 
$\mathbf{P}_{6}$ : Students' perception of their ESE will mediate the relationship between gender and their EAOs.

Theoretically, self-efficacy has mediating effects on individual thought and action (Bandura, 2001). Empirically, an increasingly growing line of applied entrepreneurship research confirms the indirect significance of ESE on entrepreneurial attitudes and behavior (Luthans, Stajkovic, and Ibrayeva, 2000). As a test of the above, the researcher performed a partial correlation test, controlling for ESE, in the examination of the relationship between gender and students' perception of their EAOs. Results showed that when controlling for students' perception of their ESE, the relationship between gender and students' perception of their EAOs weakened and changed into an inverse relationship between gender and students' perception of their EAOs $(\mathrm{R}=-0.0062, \mathrm{p}>.887)$. This suggests that (i) when the ESE variable was removed females had more unfavorable EAOs and (ii) suggests that their perception of the ESE significantly alters their EAOs.

\section{DISCUSSION}

Theoretically, social cognitive theory as a socio-psychological approach promises insightful attitudinal and behavioral revelations (Luthans and Ibrayeva, 2006). Given the above, this study applied and tested the social cognitive theory model of students' EAOs from developing countries in the Caribbean. Using such an approach, it is the hope of the researcher that by applying Bandura's $(1986,2001)$ social cognitive theory and the ESE construct as its applied derivative, more comprehensive understandings of EAOs and the processes by which they can be fostered in developing countries like the Caribbean can be attained. The unique contribution of this paper therefore is that it explores the theoretically claimed simultaneous direct and indirect interactional effects on ESE on students' EAOs.

Self-efficacy as a personal and social construct remains one of the core concepts of social cognitive theory (Bandura, 2001; Luthans and Ibrayeva, 2006). Empirically, the significance of students' perception of the ESE as a mediating and direct variable in this study provides initial empirical evidence of the predictive validity of the model. In that regard, the findings showed that ESE as a social and personal construct acts as the most valuable predictor of EAOs. This finding is consistent with that of entrepreneurial intention studies (Krueger, 2000; Boyd and Vozikis, 2004). In terms of its indirect effects, the findings also showed that correlations between gender and EAOs weakened when ESE was controlled for. Social cognitive theory explains this through its claim that self-efficacy serves as a self-regulatory mechanism that mediates external influences, as in this case, historical perceptions of gender roles, allowing these students to reflect upon and internalize these beliefs in the process of shaping their own successes or failures. As such, the findings suggest that students' EAOs can be improved through the enhancement of their ESE. Such a direction and focus hold promise for bridging and reinforcing the link between ESE and EAOs through entrepreneurial training programs (Wilson and Marlino, 2007). However, the data is silent on the role of entrepreneurial education programs in the process.

Another central tenet of social cognitive theory is the claim that personal factors like age, ethnicity, and gender affect the relationship between an individual's interaction with the environment and his/her observed attitude or behavior. As a test of this principle, the researcher explored for possible gendered variations in students' ESE and the effect of this on their EAOs. In this case, although findings showed weak associations between gender and ESE, other independent test of differences do not provide any evidence of significant gender variations in their ESE and by extension their EAOs. Interesting, what this suggests as confirmed in the qualitative analyses is that some lingering of historical gender role ideals continue to effect students' perception of their ESE, though marginal. Furthermore, thematic analyses signal the increasing recognition on the part of both male and female students that changing socio-economic patterns continue to alter the gendered interactions with environmental factors and by extension their perceptions of their possible selves. An important aspect of this 'altered gendered interaction with the environment' as identified in qualitative responses is the increasing role of women in the entrepreneurial field and by extension the labor market. Although such findings provide initial but marginal support for this theoretical proposition, it remains consistent with a stream of researchers that suggest that women are just as likely to display certain entrepreneurial competencies as men are (Bird, 1993; Muller, 2004). Theoretically, this draws on the individuals' ability to self-regulate the possible influence of external observed symbol in the environment. 


\section{IMPLICATIONS}

The study provides empirical support for the applicability of social cognitive theory to the understanding of students' EAOs in the Caribbean. While limited regional studies focused on ethnicity, religion, entrepreneurial intentions, and activities, the study took a more eclectic approach by modeling gender, ESE as useful predictors of EAOs. This approach to entrepreneurial research adds to much speculation on the relative importance of these factors in more current, changing, and developing societies like the Caribbean. However, many theoretical questions remain.

In looking specifically at environmental factors, the researcher suggests that future research explore the specific role of collective cultures as that evidenced in the Caribbean, the presence or absence of ideas on traditional gender roles, and its effects on how men and women perceive their ESE and by extension their EAOs. In that regard, such research should be based on longitudinal cross country comparisons, and examine the extent, if any, to which observed degrees of collectivistic cultures affect students' perception of their ESE and EAOs across time. Additionally, such research should also explore the processes by which cultural values manifest themselves in the social fabric of institutions like the family, education system, and the work place and in the observed EAOs. In the specific case of the predictive validity of ESE for EAOs, there is a practical need for organized efforts that develop specific entrepreneurial training and education in the Caribbean. In terms of future research, it calls for more pre and posttest research that can measure the comparative impact of these specialist entrepreneurial programs on EAOs of female and male students. Future research should also frame such explorations within the social cognitive approach as an extension of initial contributions that shed some insight into the dynamic interactions between environmental, personal factors and students' EAOs. Longitudinal studies can make significant contributions in that regard. In the meantime, cross sectional research provide some valuable insights into questions of ESE and EAOs.

In terms of national and regional policy in the Caribbean, it suggests a need for policy reform that can establish a coherent large-scale national entrepreneurial framework that provides a battery of institutional, economic, cultural, and social approaches to fostering EAOs.

\section{LIMITATIONS}

Though the study contributes to the entrepreneurial field, several limitations hinder its impact. First, the use of the survey as the primary method of investigation and the inherent inhibitions of self-reporting, the use of likert scales, and the primacy of closed ended questions in the instrument, all of which carry the potential for cognitive biases in perceptions. Second, the sample only consisted of Caribbean students enrolled in only social sciences programs within public and semi-public tertiary institutions in Trinidad. As such, the validity of its claims cannot be generalized to all tertiary students in the Caribbean. Third, the absence of a theory of entrepreneurship (Acs and Audretsch, 2005) and the testing of social cognitive theory as an alternatively integrated approach limits the operationalization of the various research constructs employed in this study, affects the measurement process related thereto, and the comparative ability of the current study to others.

\section{CONCLUSION}

The new millennium was ushered in with much anxiety and uncertainty. As we approach the completion of its first decade, the goals of entrepreneurial development remain ripe and more pressing for regional governments. In this context, the advancing pace of women entrepreneurship is a promising trend capable of fuelling economic and social development (Minnitti, Allen and Langowitz, 2005). Stemming from this recognition therefore, the findings present timely insights into initial processes by which EAOs (as an important component of the entrepreneurial development process) can be encouraged. In that regard, the major contributions of this study are the validation of social cognitive theory as an important framework for understanding the socio-cultural psychological processes involved, the unearthing of the ESE as a significant predictor of EAOs and support for further questioning of lingering notions of gender differences in ESE and EAOs. Collectively, these can provide valuable theoretical and empirical contributions to the entrepreneurial field. 


\section{AUTHOR INFORMATION}

Talia Esnard-Flavius, $\mathrm{PhD}$ is an Assistant Professor of Sociology at the University of Trinidad and Tobago. Before joining the University of Trinidad and Tobago, Dr. Flavius taught development studies at the University of the West Indies, St. Augustine campus. She has thirteen years of teaching and three years in the sociology of entrepreneurial field. Her work has focused on the supply side of entrepreneurship, looking specifically at the processes by which we engender entrepreneurial attitude orientations (EAOs) among tertiary students in the Caribbean. Most recently, her focus has been on extending her initial work on EAOs to entrepreneurial intentions

\section{REFERENCES}

1. Acs, J.Z., and Audretsch, D. B. (Eds). (2005). Handbook of Entrepreneurship Research: An Interdisciplinary Survey and Introduction (2nd ed.) New York: Springer Science and Business Media, Inc.

2. $\quad$ Acs, J. Z. and Storey, D. J. (2004). "Introduction: Entrepreneurship and Economic Development." Regional Studies, 38 (8), 871-77.

3. Allport, A. (1985). "The Historical Background of Social Psychology.” In Lindzey, G. and Aronson, E. (Ed.), Handbook of Social Psychology, Vol. 1, (3rd Ed.), pp. 1-46. New York: Random House.

4. Anna, A. L.,. Chandler, G.N.E and Mero, N.P. (2000). "Women Business Owners in Traditional and Nontraditional Industries." Journal of Business Venturing, 15, 279-303.

5. Atlantic Canada Opportunities Agency (1996). The Implementation of An Entrepreneurship Development Strategy in Canada: the Case of the Atlantic Region, (96)176, Paris, OCDE/GD

6. Bandura, A. (2001). "Social Cognitive Theory: An Agentic Perspective." Annual Review of Psychology, Vol. 52, 1-36.

7. Bandura, A. (1991). "Social Cognitive Theory of Moral Thought and Action." In Kurtines, W.M. and Gerwitz, J.L. (Ed.), Handbook of Moral Behaviour and Development, Vol. 1, pp. 45-103. New Jersey: Hillsdale.

8. $\quad$ Bandura, A.(1989). "Human Agency in Social-Cognitive Theory." American Psychologist 44, 1175-1184.

9. Bandura, A.(1986). Social Foundations of Thought and Action: A Social Cognitive Theory. Englewood Cliffs, N. J. Prentice-Hall.

10. Baum, J.R. and Locke, E. A. (2004). "The Relationship of Entrepreneurial Traits, Skill, and Motivation to Subsequent Venture Growth.” Journal of Applied Psychology 89 (4), 587-598.

11. Bird, B. (1993). "Demographic Approaches to Entrepreneurship: the Role of Experience and Background." In Katz, J. A. and Brockhaus, R.H. Sr., (Ed.), Advances in Entrepreneurship, Firm Emergence, and Growth, Vol.1, pp. 11-48. Connecticut: JAI Press Inc.

12. Bird, B. (1988). Implementing Entrepreneurial Ideas: The case for Intention. Academy of Management Review, 13(3), 442-453.

13. Brush, C.G. (1992). Research on women business owners: Past trends, a new perspective and future directions. Entrepreneurship Theory and Practice, 16(4), 5-30.

14. Brush, C.G., Carter, N.M., Gatewood, E.J., Greene, PG. \& Hart, M. (Eds.). (2006). Growth-oriented women entrepreneurs and their businesses: A global perspective. Cheltenham, U.K.: Edward Elgar.

15. Bosma, N. and Harding, R. (2007). Global Entrepreneurship Monitor: GEM 2006 results. Babson: Babson College and London School of Economics.

16. Bosma, N. and Levie, J. (2009) Global Entrepreneurship Monitor, 2009 Executive Report, Global Entrepreneurship Research Association, Babson Park, MA and London: Babson College and London Business School.

17. Boyd, N., and Vozikis, G.S. (1994). "The Influence of Self-Efficacy on the Development of Entrepreneurial Intent and Actions." Entrepreneurship Theory and Practice, Vol. 2, 63-77.

18. Bridge, S., O'Neil, K., and Cromie, S. (2003). Understanding Enterprise: Entrepreneurship and Small Business, $\left({ }^{\text {nd }}\right.$ Ed.), Great Britain: Palgrave Macmillan.

19. Brockhaus, R. H. Sr. (1993). Series Introduction, Advances in Entrepreneurship, Firm Emergence, and Growth. Vol.1, 1-5. JAI Press Inc.

20. Brockhaus, R. H. Sr. (1987). "Entrepreneurial Folklore” Journal of Small Business Management 29 (3), 62-74. 
21. Brodsky, M.A. (1993). "Successful Female Corporate Managers and Entrepreneurs: Similarities and differences." Group and Organization management 18(3), 366-78.

22. Bygrave, W.D. (1994). The Portable MBA in Entrepreneurship. New York, NY: John Wiley and Sons, Inc.

23. Casrud, L.A. and Johnson, R.W. (1989). "Entrepreneurship: A Social Psychological Perspective.” Entrepreneurship Theory and Regional Development: an International Journal 1 (1), 21-31.

24. Casson, M. (1982). The Entrepreneur: An Economic Theory. Oxford: Martin Robertson.

25. Chen, C., Greene, P.G. and Crick, A. (1998). "Does Entrepreneurial Self-efficacy Distinguish Entrepreneurs from Managers." Journal of Business Venturing, 13, 295-316.

26. Delmar, F and Davidsson, P. (2000) Where do they come from? Prevalence and Ccharacteristics of Nascent Entrepreneurs, Entrepreneurship and Regional Development, 12, 1-23.

27. DeNoble, A., Jung, D., and Ehrlich, S. (1999). "Entrepreneurial Self-efficacy: The Development of a Measure and its Relationship to Entrepreneurial Action." Paper presented at the Babson-Kauffman Entrepreneurial Research conference.

28. Drucker, P. (1985). Innovation and Entrepreneurship: Practice and Principles. London: Heinemann.

29. European Commission. (2004). "Implementation of Education \& Training 2010", Working Group B: Key Competencies-Entrepreneurship Education and Learning: aEC.

30. Ferdinand, C. (2001). (Ed.) "Jobs, Gender, and the Small Enterprise in the Caribbean: Lessons from Barbados, Suriname, and Trinidad and Tobago." Series on Women's Entrepreneurship Development and Gender in Enterprises (WEDGE), Geneva: International Labour Office.

31. Gartner, W. B. (1985). "A Conceptual Framework for Describing the Phenomenon of New Venture Creation." Academy of Management Review 10 (4), 696-706.

32. Gatewood, E.G., Carter, N.M., Brush, C.G., Greene, P.G., \& Hart, M.M. (2003). Women Entrepreneurs, their Ventures, and the Venture Capital Industry: An annotated bibliography. Stockholm: ESBRI

33. Hofstede, G. (2001). Culture's Consequences: Comparing Values, Behaviours, Institutions, and Organizations across Nations, ( $2^{\text {nd }}$ Ed.). CA: Sage.

34. Katz, A.J., Brockhaus, R.H. Sr., and Hills, G. (1993). "Demographic Variables in Entrepreneurship Research.” In . Katz, J. and Brockhaus, R. H. Sr. (Ed.), Advances in Entrepreneurship, Firm Emergence, and Growth, Vol. 1, pp. 197-213. Connecticut: JAI.

35. Kirzner, I.M. (1997) "Entrepreneurial Discovery and the Competitive Market Process: An Austrian Approach." Journal of Economic Literature 35 (1), 60-85.

36. Krueger, N. F. (2005). "The Cognitive Psychology of Entrepreneurship.” In Acs, Z.J. and Audretsch, D.B (Eds.), Handbook of Entrepreneurship Research: An Interdisciplinary Survey and Introduction, pp. 106140, New York: Springer.

37. Krueger, N. F. (2000). "The cognitive Infrastructure of Opportunity Emergence." Entrepreneurship Theory and Practice 24 (3), 5-23.

38. Krueger, N. F. (1993). "The Impact of Prior Entrepreneurial Exposure on Perceptions of New Venture Feasibility and Desirability." Entrepreneurship Theory and Practice 18(1), 5-21.

39. Krueger, N.F. and Brazeal, D.V. (1994). "Entrepreneurial Potential and Potential Entrepreneurs." Entrepreneurship Theory and Practice 18(3), 91-105.

40. Krueger, N. F. Jr., Reilly, M.D., Casrud, A.L. (2000). “Competing Models of Entrepreneurial Intentions.” Journal of Business Venturing 15, 411-32.

41. Langlois, R. N. (2001). "Knowledge, Consumption and Endogenous Growth." Journal of Evolutionary Economics 11, 77-93.

42. Lisoskwa, E. (2002). "Women's Entrepreneurship: Trends, Motivations, and Barriers.” In United Nations Economic Commission for Europe, Women's Entrepreneurship in Eastern Europe and the CIS countries Series: Entrepreneurship and SMEs, pp. 23-43, Geneva, UNECE.

43. Low, M. (2001). The adolescence of entrepreneurship research: Specification of purpose. "Entrepreneurship Theory and Practice", 25(4), 17-25.

44. Luthans, F., and Ibrayeva, E.S. (2006). "Entrepreneurial Self-Efficacy in Central Asian Transition Economies: Quantitative and Qualitative Analyses.” Journal of International Business Studies 37(92), 92110 .

45. Luthans, F., Stajkovic, A.D. and Ibrayeva, E. (2000). "Environment and Psychological Challenges Facing Entrepreneurial Development in Transition Economies." Journal of World Business 35 (1), 95-110. 
46. Mau, W.-C. (2003). "Factors Influences Persistence in Science and Engineering Career Aspirations." The Career Development Quarterly, 51, 234-43.

47. McGee, E. J., Peterson, M., Mueller, L.S., Sequeria, M. J. (2009) "Entrepreneurial Self-Efficacy: refining the measure", Entrepreneurship Theory and Practice, Vol. 28 (2), 129-144.

48. Minitti, M., Arenius, P., \& Langowitz, N. (2005). Global entrepreneurship monitor: 2004 report on women and entrepreneurship. Babson Park, MA and London: Babson College and London Business School

49. Muller, S.L. and Dato-On, M.C. (2008) Journal of Developmental Entrepreneurship, Vol. 13 (1), 3-20.

50. Muller, S. L., and Thomas, S.A. (2001). "Culture and Entrepreneurial Potential: A Nine Country Study of Locus of Control and Innovativeness." Journal of Business Venturing 16(1), 51-75.

51. Mueller, S. L. (2004) Gender Gaps in Potential for Entrepreneurship Across Countries and Cultures, Journal of Developmental Entrepreneurship 9 (3), 199-220.

52. Reynold, P., W.D. Bygrave, and E. Autio (2004). GEM 2003 Global Report. Babson Park, MA: Babson College; London, UK: London Business School, and Kansas City, MO: Kauffman Foundation.

53. Robinson, P. B., Stimpson, D.V., Huefer, J.V. and Hunt, H. K. (1991). "An Attitude Approach to the Prediction of Entrepreneurship." Entrepreneurship Theory and Practice 15(4), 13-31.

54. Ronstadt, R. (1990). "The Educated Entrepreneurs: A New Era of Entrepreneurial Education is beginning." In Kent, C.A. (Ed.), Entrepreneurship Education: Current Developments, Future Directions, pp. 68-88. New York: Quorum Books.

55. Rotter, J.B. (1966). "Generalized Expectancies for Internal versus External Control of Reinforcement." Psychological Monographs 80 (1), 1-28.

56. Ruminska-Zimmy, E. (2002). "Women's Entrepreneurship and Labour Market Trends in Transition Countries." In ." In United Nations Economic Commission for Europe, Women's Entrepreneurship in Eastern Europe and the CIS countries Series: Entrepreneurship and SMEs, pp. 7-21, Geneva, UNECE.

57. Rushing, W. F. (1990). "Entrepreneurship and Education.” In Kent, C. A. (Ed.), Entrepreneurship Education: Current Developments and Future Directions, pp. 29-40. New York: Quorum Books.

58. Schumpeter, J. A. (1934) "The theory of Economic Development: An inquiry into profits, Capital, Credit, Interest, and the Business Cycles." Harvard Business Review 25 (1), 217-226.

59. Shapero, A., and Sokol, L. (1982). "The Social Dimensions of Entrepreneurship.” In Kent, C., Sexton, D., and Vesper, K. (Ed.), The Encyclopedia of Entrepreneurship, pp. 72-90, Englewood Cliffs: Prentice Hall.

60. U. S. Small Business Administration (USSBA), Office of Advocacy (1997) Economic Census: Survey of Minority-Owned Business Enterprises. Washington, D.C.: Government Printing Office.

61. Ward, E.A. (1993). "Motivation of Expansion Plans of Entrepreneurs and Small Business Managers (Measuring Locus of Control)." Journal of Small Business Management 31, 32-38.

62. William J. E. and Best, D.L. (1982) Measuring Sex Stereotypes, Beverly Hills, CA: Sage Publications.

63. Wilson, F., Kickul, J., \& Marlino, D. (2007). Gender, Entrepreneurial Self-Efficacy and Entrepreneurial Career Intentions: Implications for Entrepreneurship Education. "Entrepreneurship Theory and Practice", Vol 31 (3), 387-406. 
NOTES 